\title{
Role of Information Technology in Healthcare Services: Visitor's Perception
}

\author{
Santosh Kumar Sharma ${ }^{* 1}$ and Anil Kumar ${ }^{2}$ \\ ${ }^{1}$ Institute of Management, Jammu, Jammu and Kashmir-180016, India \\ ${ }^{2}$ Fortis Hospital, Sector 62, Sahibzada Ajit Singh Nagar, Punjab-160062, India
}

"Email: santosh.sharma@iimj.ac.in

\section{ARTICLE INFORMATION}

Received: February 02, 2018

Revised: February 22, 2018

Accepted: March 01, 2018

Published online: April 02, 2018

Keywords:

Healthcare, Services, Information Technology

DOI: https://doi.org/10.15415/jmrh.2017.42007

\section{ABSTRACT}

The aging population, increasing pollution, and lethargic life style of human beings are some of the primary reasons for the growth of healthcare sector. Indian entrepreneurs have observed this growth opportunities and providing healthcare services in multiple ways. However, the literature emphasizes that without integrating information technology in existing healthcare facilities, quality service cannot be rendered to a large number of patients. With this backdrop, the present study is a novel endeavor to explore the role of information technology in Indian healthcare services. It aims to explain the relevance and dimensions of information technology in relation to healthcare services and examines the empirical relationship between identified dimensions and some demographical factors (age, educational qualification, income, and gender).The results of this study can be beneficial to healthcare professionals, service enablers, implementing agencies, and policy makers. Limitations, further research directions and conclusions have been discussed.

\section{Introduction}

History of the human evolution is a testimony of the fact that human beings have always struggled for the survival and in most cases the Darwin's notion of "Survival of the Fittest" hold true. Analogical to this testimony this is quite natural to assume that with the increasing complexities in professional and personal life most of the times people engage themselves in excessive targets and role demands. In common parlance we can say that in order to survive in family, personal relations, and professional life we always strive to stretch our abilities, skills, and capacities ranging from mental to physical. However, in this journey of survival most of the time we neglect our health consciously or unconsciously which result into visits to hospitals and healthcare centers. Moreover, recent research indicates with the increasing environmental pollution (Mohan, 2017; Rizwan et. al., 2013; Kelishadi, 2012; Remoundou and Koundouri, 2009) and complex life style (Farhud, 2015; Stanley and Laugharne, 2014; Walsh, 2011), the issue of health has become an important concern. At this juncture it is worthwhile to note that whatever be the reason for health concerns we tend to take care it (health) by visiting the hospitals or healthcare center which not only creates hurdles for progressive life by reducing work efficiency and productivity but also induces spillover effect on visitors (family members, relatives, and friends of the patient). We can observe that in India whenever a patients visits to hospitals or healthcare centers, he or she is accompanied by few family members, relatives or friends who spares their valuable time with the patients for their medical checkup and treatment. However, due to the increasing role demands in personal and professional domains people have scarcity of time and thereby hesitate to invest any productive moment with the patient's medical care. Recently, we witnessed a case where the son of a professor said that "Because of my commuting distance and professional challenges it is very difficult for me to accompany my father in his several visits to hospital. This son elaborated that there are many hospitals or healthcare centers which are unable to process all the required functions and provide healthcare services at one go". From this conversation we deduced that in the contemporary era of nuclear families and professional liabilities it is difficult for people to invest a lot of time in undesirable activities related to medical diagnosis, treatments, and report collection and therefore we can argue that there will be increasing need of technology enabled healthcare 
services. Moreover, World Health Resolution (67/13) it is expected that by 2050 the world's population aged 60 years and older is expected to total 2 billion, up from 900 million in 2015 out of which $80 \%$ of all older people will live in low- and middle-income countries. There is no doubt that these demographical changes will bring many societal benefits primarily in terms of mentorship rendered by these old aged people to younger generations or millennials and career opportunities for old-aged people even after retirement from jobs (if they wish) but it will also forward many challenges before associated stakeholders (government, hospitals, healthcare centers etc.) to provide healthcare services to these old-aged people. To provide these healthcare services in urban areas is relatively easy as compare to rural areas but it is difficult in rural and remote areas because of infrastructural problems, lack of manpower (doctors, paramedical staff, administrative executives etc.) coupled with geographical terrains. Therefore, it is the need of hour that information technology should be integrated in existing healthcare facilities to an optimum level. With these backdrops, when we meticulously searched the relevant and available literature further we found that there are many scholarly works (research studies) in the said direction. Some of these studies which have highlighted the role of information technology in healthcare services are, medical tourism (Moghavvemi et. al., 2016), material management in intensive care units (Huang et al., 2016), hospital efficiency (Cho et al., 2016), patient's safety and quality of care (Seblega, 2015), cost optimization, quality, patient experience, strategy, and organization culture (Cline and Luiz, 2013; Ortiz and Clancy, 2003), quality of health information (Li et al., 2012), outpatient appointment systems (Wijewickrama and Takakuwa, 2012), clinical decision making (Byrd and Byrd, 2012), bed-monitoring system (Lu, 2012), emergency medical services (Ahmed et al., 2010), efficiency and equity (Testi et al., 2009), patient's satisfaction with web based information during surgical intervention (Koop et al., 2010), economic implications and the patient satisfaction (Masella and Zanaboni, 2009), postoperative patient monitoring (Rajasekaran et al., 2008), financial Impact (Ohsfeldt et al., 2005), medication safety (Kaushal et al., 2003), new kinds of employment in health-related professions (Masys, 2002), and reduction of medical error (Bates et al., 2001). Apart from the aforementioned studies other studies which have indicated the potential role of information technology in healthcare services are, Otte-Trojel et al., 2017; Patwardhan et al., 2017; Thomas and Woodside, 2016; Schultz et al., 2016; Zhan, et al., 2016; Sintonen et al., 2015; Wang, 2015; Steiner, 2014; Mosadeghrad, 2014; Ozcan and Legg, 2014; Mehraeen et al., 2014; Thangaraj and Gnanambal; 2014; Miah, 2014; Bhangale, 2011; Henschke et al., 2010; Herrick et al., 2010; Alasaarela et al., 2009; Whetstone and Randeree, 2008; Pui-Mun, 2004; Duplaga, 2004; Chaua and Hub, 2002; Buntin et al., 2002; and Bates et al., 2001. However, only few studies have been conducted from Asian perspective especially with reference to India (Venkateswaran et al., 2016; Srinivas and Prasad, 2013; Kavitha, 2013; Itumalla, 2012). This research gap motivated us to undertake the present study with the following objectives.

\subsection{Objectives}

1. To explain relevance of information technology in Indian healthcare sector

2. To identify dimensions of information technology in healthcare services

3. To propose a scale to measure visitor's perspectives in reference to applications of information technology in healthcare services

4. To analyze the relationship between identified dimensions of information technology and demographical factors (Age, Educational Qualification, Income and Gender)

To meet these objectives we have undergone through a meticulous literature review and analyzed the collected data statistically with the help of SPSS software (Version 20).

\section{Literature Review}

The Indian health care sector is expected to reach U.S. $\$ 280$ billion by 2020 (India Brand Equity Foundation, 2017). In such a scenario government is expected to invest a huge amount of money in healthcare sector of India. However, due to some structural constraints there will also be a need of private hospitals to serve a larger population of India. On one hand, it has been observed that most of these hospitals are located in urban areas and competing with each other on several grounds in order to remain sustainable in the healthcare market. However, on the other hand there are some hospitals which are applying the blue ocean strategy and trying to tap the rural areas of India through the use of information and communication technology (ICT). In such a scenario it is worthwhile to understand the role of information technology in healthcare services which has been attempted through the present study. In this context when we scrutinized the literature we found that that there is a growing interest among the researchers to examine the role of information technology in healthcare services which motivated us further to review few more scholarly articles which are presented as follows. 
Venkateswaran et al., (2016) have analyzed the impression of telemedicine on patient happiness in the rural area. The study concludes that by applying information technology in healthcare services some improvements may be done in clinical governance, professional relationship between patient and doctor, and patient's satisfaction. Moghavvemi et al., (2016) have examined the medical tourism scenario in competing Asian countries (India, Malaysia and Thailand) and concluded that information technology is highly useful for showcasing and promoting destinations medical facilities through online presence. Mohapatra and Murarka (2016) have concluded that using technology to maintain electronic healthcare records (EHR) improves performance of healthcare services and also optimizes cost. In a descriptive study, Khanna and Narula (2016) have shown the applicability of mobile health units (MHUs) in public health. In a comparative study of healthcare providers, Seblega et al., (2015) have found differences in patient outcomes on the basis of healthcare information technology. Sintonen et al. (2015) have analyzed the feasibility of electronic health record system in a regional hospital in south-eastern Finland and found that a system's complexity and problems with reliability negatively influence its usefulness and decrease the willingness of personnel to use the healthcare information technology. In a sample of 623 healthcare providers in Saudi Arabia, Bennett et al., (2015) have examined the role of demographical factors on employee's perceptions of healthcare information technology. The results indicated that employees with longer tenure perceived fewer benefits and more barriers in applying information technology in healthcare services. However, the study highlighted that females perceived more benefits and fewer barriers as compared to than males. The study concludes that if effective training is designed and delivered in the area of healthcare information technology, benefits could be given to associated stakeholders. Mohapatra (2015) explains how hospital information system (HIS) is used as a comprehensive and integrated information system designed to manage the administrative, financial, and clinical aspects of a hospital in urban India. The case also illustrates how the information system ensures financial returns by improving timeliness of patient care, accounting and administration, record keeping, and management reporting. Ornes et al., (2014) suggest the role of information technology in designing and managing a website that can engage patients and their family members during care. In a descriptive cross-sectional study, Mehraeen et al., (2014) have evaluated indices of hospital information systems (HIS) in selected hospitals of Iran. The study concludes that evaluation indexes checklist includes 9 organizational components and 11 hospital information system server components, along with the main subgroups and also their subsidiary subgroups. In a descriptive research conducted in private and government hospital in and around Hyderabad, Srinivas and Prasad (2013) have underlined some of the key reasons for selecting hospitals in India. These primary reasons are oriented towards referral system (where hospital is referred by friends, family members), carefulness of the doctors while treating the patient, behavior of doctors, and safety of the patients. The study concludes that by keeping all these reasons in mind it is necessary to bring latest technology in healthcare services at affordable price. By using technology acceptance model, Noblin et al., (2013) have studied the inclination of patients to use a personal health record if it is made available in the future. The study concludes that the technology barriers and perceived usefulness of a personal health record is a significant determining factor regarding user's intention to adopt the technology. The study suggests that by providing hands-on training to office staff can enhance perceived usefulness and remove barriers. From the economic and social perspective, Kavitha (2013) has examined the factors driving the influence of information technology in Indian healthcare, maintenance of computerized patient records in urban and rural areas of India. The adoption of information technology in healthcare services is been extensively accepted and implemented in urban areas rather rural areas of Indian scenario because of various factors such as lack of resources, technical (computer) skills among staff, standard policy framework etc. Chow (2013) observes that urban location and hospital type and size are associated with the use of information technology in healthcare services. Cline and Luiz (2013) have examined the impact of hospital information systems implementation on service delivery, user adoption and organizational culture within two hospital settings in South Africa. By using structured questionnaires they have conducted 94 interviews with doctors, nurses and hospital administrators to record end-user perceptions. The results indicate that there are statistical differences among the three sample groups of doctors, nurses and administrators as well as two hospital groups. The study highlights that automation can reduce cost and provide strategic values to the healthcare providers in terms of patient experience, hospital staff workflow enhancements, and overall morale in the workplace. Wijewickrama and Takakuwa (2012) have noted the importance of online patient's appointment systems according to patient characteristics. The study concludes that such kind of appointment systems may trade-off between patient waiting time and physician idle time. Li $e t$ al., (2012) have performed a comparative analysis of the quality of online health information in China, India, and the USA and recommends for improvements to health information portals in two countries (China and India). By 
focusing on real-time data $\mathrm{Lu}$ (2012) has developed a smart bed-monitoring application using a ZigBee sensor network. The researcher believes that this application can be implemented to enable the physicians and the caregivers to access patient data so that they can respond instantly to any irregularity in the condition of in-bed patients. Koop et al., (2010) examines the patient satisfaction when he or she is informed through web application during surgical interventions. The results indicate that patients are more satisfied when information is given through web application and also predicts that multimedia information techniques will be highly used in healthcare in the near future. Recognizing the importance of waiting lists for elective surgery as a significant issue in many publicly funded health systems, Testi et al., (2009) recommends for the web-based informative system for prioritizing elective surgery admissions and producing reports about the performance of waiting lists in terms of efficiency and equity indexes. By analyzing clinical, technological and business challenges of healthcare services in remote and rural areas Darkins and Sanders (2009) have shown the importance of postdischarge healthcare services through information technology. Rajasekaran et al., (2008) have delineated the need of information technology in post-operative health care services. The researchers have developed, a real-time patient monitoring system that integrates a vital signs sensor, a sensor network, electronic patient records and web portal technology to allow remote monitoring of postoperative patient status in the hospital and homecare conditions and to alert medical personnel when lifethreatening events occur. They strongly believe that such kind of systems will facilitate communication among patients, medical professionals and specialists available for consultation from distant places which will eventually contribute in reducing the healthcare costs. Ohsfeldt et al. (2005) have evaluated the financial implications of integrating information technology in healthcare services especially in the context of rural areas. The study concludes that implementation of information technology (computerized physician order) in hospitals depends on net increase in operating costs and therefore it is not feasible in case of small hospitals until some subsidies are given through government or third party. Masys (2002) has examined the healthcare information technology from the perspective of Human Resources and employment opportunities. The author argues that the growth of consumerism and the proliferation of Internet-accessible sources of health-related information will modify the traditional roles of provider and patient and thereby will create new opportunities for employment in health-related professions. Bates et al., (2001) have described how the frequency and consequences of errors in medical care can be reduced (although in some instances they are potentiated) by the use of information technology. The study recommends computerized prescribing, bar-coding for medications, blood, devices, and patients and eventually concludes that by applying information technology in healthcare services there will be better linkages in and among systems (clinical decision support) resulting in process simplification and substantial improvement in patient safety.

In the light of aforementioned scholarly works it can be summarized that there are diversified views and research outcome regarding application of information technology in healthcare services. However, most of the studies are conducted in foreign countries (outside of India) where citizens may have unique point of view regarding technological implications in healthcare services which restrict the findings to implicate in India. Moreover, most of the extant literature has considered healthcare services from the provider's perspective rather than patient' 3 s perspective. Therefore, with this research lacuna, the present study aims to explain the relevance and dimensions of information technology in relation to Indian healthcare services and examines the empirical relationship between identified dimensions and some demographical factors (age, educational qualification, income, and gender).

\section{Methodology}

\subsection{Sample}

Initially, we prepared a list of target population (150 potential respondents) who are faculty members, staff, and students of a premium technical institute of India. This academic sample has been selected because we assume that these people are visiting or have definitely visited hospitals or healthcare center at some point of time. We have divided this target population in different strata based on the hierarchy in the institute (Professors, Associate Professors, Assistant Professor, Staff, and Students). The most plausible reason for dividing the target population in different strata is that it may generate variation in our demographical variables (age, gender, monthly income and educational qualification) which will help us in interpreting the results in a meaningful way. We distributed the self-developed questionnaire to the approachable respondents (98) and briefed them about the purpose of this academic endeavor and data collection. We also assured the respondents that their data will be kept confidential and only used for research purpose. We received 60 questionnaires out of which 57 were complete in all respect. As we approached each respondent personally by taking prior appointment, we received the questionnaires in total four days mostly on spot. 


\subsection{Questionnaire}

Drawing on the aforementioned literature, a questionnaire has been developed to explore the role of information technology on healthcare services. This questionnaire comprises three sections. First section (Section-A) includes four demographical variables of respondents namely; age, gender, educational qualification, and monthly income. The first variable 'age' has been selected because we assume that it plays important role in deciding hospital type and location. For instance, when an old age patient suffers from critical diseases he or she prefers to be admitted in nearby hospitals or healthcare centers because of his/her dependency on family members, relatives or friends who face difficulty in sparing their productive time to accompany the patient for a distant hospital/healthcare center. However, if a patient is of young age he/she is able to move independently towards a distant hospitals or healthcare centers. The second variable 'gender' has been selected because it has been observed that during medical treatments especially in pregnancy women prefer to be admitted in nearby hospitals or healthcare centers. The most plausible reason for this may be understood from the psychological perspective. For instance when female moves out of her home she carries many household activities in mind which restricts her decision in selecting the hospital for treatment. The third variable 'educational qualification' has been selected because of two reasons. In the first reason we assume that highly educated people are aware about the modern applications of information technology and thereby would prefer technology enabled healthcare services. In the second reason we assume that highly educated people invest their maximum time in jobs or business activities and therefore would like to save their productive time by accessing healthcare services through information technology. The fourth variable 'monthly income' has been selected because in modern time it is common to have electronic gadgets (mobile, laptop etc.) and internet facilities which demands a reasonable monthly income especially in rural areas of India. When we discussed the relevance of aforementioned demographical variables with various male and female members of different communities and societies we were assured that we have selected these variables in a rationale way.

The second section (Section-B) of the questionnaire includes fifteen closed ended statements (items) which have been generated on the basis of literature review. The content validity of these fifteen items were assured by expertise of the academic (5 experts) and medical professionals (5 experts). For each item experts were given brief introduction about the possible integration of information technology with healthcare services. The experts responded dichotomously (yes/no) which guided us for inclusion or deletion of the item from this section of questionnaire. The third section (Section-C) of the questionnaire includes two open ended questions in order to know their view regarding selection of hospitals and inclination towards paying extra amount of money for accessing technology enabled healthcare services in future.

\subsection{Data Analysis}

Instead of replacing the missing values in uncompleted questionnaire through statistical procedures we preferred to eliminate that questionnaire because according to SPSS white paper (https://www.bauer.uh.edu/jhess/documents/2. pdf, p.3) missing data can lead to misleading results. Finally, data collected through 57 questionnaires have been used for further analyses by applying statistical techniques through widely acknowledged SPSS software. Results of these analyses have been presented in the following section along with discussions.

\section{Results and Discussions}

To meet the Objective 1 (relevance of information technology in Indian healthcare sector) we reviewed the available literature and found that there are few studies (Mohapatra and Murarka, 2016; Venkateswaran et al., 2016; Mohapatra, 2015; Srinivas and Prasad, 2013; Kavitha, 2013; Itumalla, 2012; Rajasekaran et al., 2008) which have delineated this issue and strongly support the relevance of information technology in Indian healthcare sector. However, these studies are silent on explaining the relevance from socio-economic point of view. At this juncture we would like to bring the attention of our readers that in India, a large population stays in rural area which lacks state of the art medical facilities. If we talk about the urban cities the situation is better. However, there are many cases (authors' experiences during medical treatments of their parents and relatives) in which patients are the referred to the tier- 1 cities only (Delhi, Mumbai, Chennai, Kolkata, Bengaluru) for better treatments and medical facilities. In these situations it is a compelling question that what will happen to those patients or families who cannot afford financial burden during travelling and staying the aforementioned big cities (Pillai, 2013). The most plausible solution for such kind of issues may be given by high integration of information technology in Indian healthcare services such as telemedicine and others. In response to this objective 1 , when we collected the data (please see the item number-18 in questionnaire) we found that out of 57 questionnaires, 56 have the 'Yes' response which indicates that $98.2 \%$ respondents agree that they will prefer those hospitals and healthcare centers that provides technology enabled healthcare services. This result implies the high relevance of information technology in Indian healthcare sector. 
To meet the objective 2 (dimensions of information technology in healthcare services) when we searched the literature we could not find any article that deliberate on dimensions of information technology in relation to healthcare services. Therefore, based on fifteen items of the self-developed questionnaire (Section-B) we have classified healthcare information technology in to three dimensions namely; Pre-Visit Technology Services (PVTS) which consist of six items, During Treatment Technology Services (DTTS) which consist of five items, and Post-Discharge Technology Services (PDTS) which consists of six items. The Cronbach's alpha of all these dimensions $(.62, .74$, and .74) confirms the reliability of the overall scale (Sapp and Jensen, 1997). KMO test (Table 1) indicates that the given sample is sufficient to apply factor analysis.

Table 1: KMO and Bartlett's Test.

\begin{tabular}{|l|l|l|}
\hline $\begin{array}{l}\text { Kaiser-Meyer-Olkin } \\
\text { Measure of Sampling }\end{array}$ & & \\
\hline Adequacy. & & .685 \\
\hline & Approx. Chi-Square & 331.619 \\
\hline Bartlett's Test of Sphericity & & \\
\hline & Df & 136 \\
\hline & Sig. & .000 \\
\hline
\end{tabular}

All the three identified dimensions of healthcare information technology (PVTS, DTTS, and PDTS) are verified through exploratory factor analysis and scree plot as shown in Figure 1.

Scree Plot

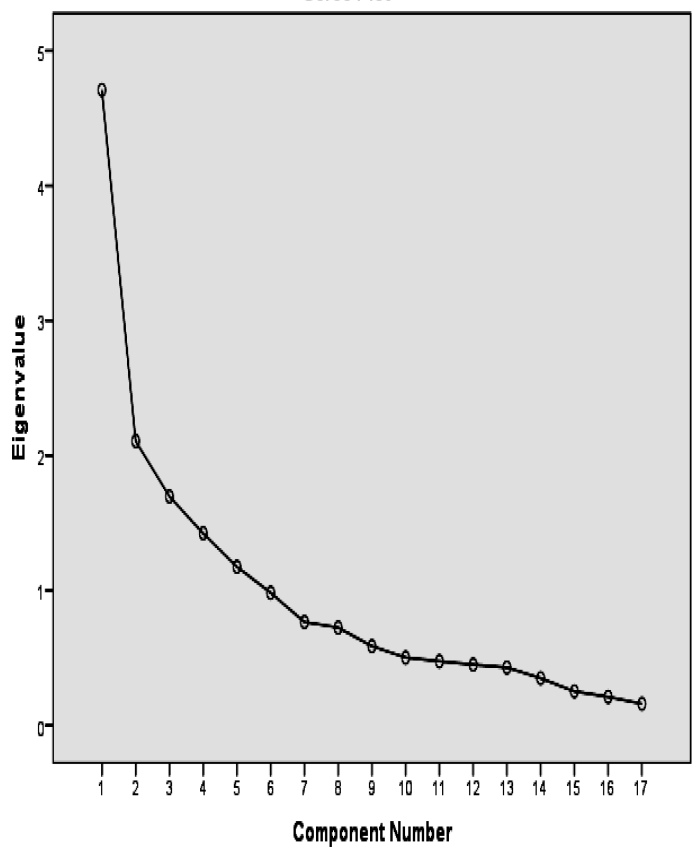

Figure 1
The above results were discussed with medical experts and academic researchers and accordingly the scale (Section-B of the Questionnaire) has been proposed to measure visitor's perspectives regarding applications of information technology in healthcare services. Herein after this scale is termed as RITHS scale, i.e. Role of Information Technology in Healthcare Services and therefore objective 3 has been achieved. The objective 4 of the present study is to examine empirical relationship between identified dimensions of healthcare information technology (PVTS, DTTS, and PDTS) and demographical factors (Age, Educational Qualification, Income and Gender) which has been achieved by applying various statistical analyses with the help of SPSS software. These analyses are presented as below.

Table 2: Pearson Correlation between age, income, and identified dimensions of Healthcare Information Technology (PVTS, DTTS, and PDTS).

\begin{tabular}{|l|l|l|l|l|}
\hline Variables & PVTS & DTTS & PDTS & Income \\
\hline Age & $.42^{* *}$ & -.11 & -.02 & .84 \\
\hline Income & $.47^{* *}$ & .05 & .09 & 1 \\
\hline
\end{tabular}

Note: ${ }^{* *} \mathrm{p}<0.01$., PVTS= Pre-Visit Technology Services; DTTS= During Treatment Technology Services; PDTS= Post-Discharge Technology Services

From Table 2, it is evident that as age increases income increases which is a common fact because in India when age increases people are succumbed to more responsibilities so by choice or force they have to increase their income. It is also visible in this Table 2 that out of all the three dimensions of healthcare information technology (PVTS, DTTS, and PDTS) only one dimension (PVTS) has positive and significant relationship with age and income. This implies that as age and income increases people are more inclined towards accessing healthcare services through information technology before visiting hospitals or healthcare centers physically. Although the literature is silent to corroborate or refute this kind of novel result but if we see the healthcare scenario in India we can note that many hospitals and healthcare centers are working on multi-dimensions of technology to attract the prospective patients and market their services.

Further, as it is mentioned in preceding text of this article that higher education may lead to adoption of technology in healthcare services, it is reasonable to analyze the relationship and significance of identified dimensions of healthcare information technology (PVTS, DTTS, and PDTS) across educational qualification of the respondents in sample. As we have four categories of educational qualifications (PhD/Post-Graduation/Graduation/Others) 
we would like to apply one-way ANOVA analysis which is presented as below in Table 3. Table 3: ANOVA

Table 3: ANOVA

\begin{tabular}{|c|c|c|c|c|c|c|}
\hline & & $\begin{array}{l}\text { Sum of } \\
\text { Squares }\end{array}$ & df & $\begin{array}{l}\text { Mean } \\
\text { Square }\end{array}$ & $\mathbf{F}$ & Sig. \\
\hline & Between & \multirow{2}{*}{76.654} & \multirow{2}{*}{2} & \multirow{2}{*}{38.327} & \multirow{2}{*}{2.101} & \multirow{2}{*}{.132} \\
\hline & Groups & & & & & \\
\hline \multicolumn{7}{|l|}{ PVTS } \\
\hline & $\begin{array}{l}\text { Within } \\
\text { Groups }\end{array}$ & 984.925 & 54 & 18.239 & & \\
\hline & Total & 1061.579 & 56 & & & \\
\hline & Between & \multirow{2}{*}{47.544} & \multirow{2}{*}{2} & \multirow{2}{*}{23.772} & \multirow{2}{*}{1.317} & \multirow{2}{*}{.276} \\
\hline & Groups & & & & & \\
\hline \multicolumn{7}{|l|}{ DTTS } \\
\hline & $\begin{array}{l}\text { Within } \\
\text { Groups }\end{array}$ & 974.596 & 54 & 18.048 & & \\
\hline & Total & 1022.140 & 56 & & & \\
\hline & Between & \multirow{2}{*}{56.589} & \multirow{2}{*}{2} & \multirow{2}{*}{28.295} & \multirow{2}{*}{1.669} & \multirow{2}{*}{.198} \\
\hline & Groups & & & & & \\
\hline \multicolumn{7}{|l|}{ PDTS } \\
\hline & $\begin{array}{l}\text { Within } \\
\text { Groups }\end{array}$ & 915.551 & 54 & 16.955 & & \\
\hline & Total & 972.140 & 56 & & & \\
\hline
\end{tabular}

From this Table 3, it is clear that there is no difference in identified dimensions of healthcare information technology (PVTS, DTTS, and PDTS) across education qualifications of the respondents in sample which implies that people in India need technology enabled healthcare services irrespective of their educational qualifications. The possible reason for such kind of result may be that in recent times there is a high penetration of internet and technology enabled devices due to which all the generations feel themselves quite comfortable in accessing healthcare services through information technology. Moreover, to understand the relationship and significance of identified dimensions of healthcare information technology (PVTS, DTTS, and PDTS) across gender we have applied independent sample $\mathrm{t}$-Test. The results of this $\mathrm{t}$-Test are as follows:

(a) There is no significant difference in the dimension PVTS for male $(\mathrm{M}=33.60, \mathrm{SD}=4.88)$ and female $(\mathrm{M}=34.23, \mathrm{SD}=3.44) ; \mathrm{t}(55)=-.53, \mathrm{p}=.60$; which signifies that gender has no role in explaining 'pre-visit technology services' (PVTS) related to healthcare. The strongest reason for this kind of result could be explained in the light of increasing women empowerment and special campaign for Beti Bachao, Beti Padhao Yojana launched by Government of India which has given momentum to the technology enabled skill development among Indians especially people at premium technical institutions of the country.

(b) There is no significant difference in the dimension DTTS for male $(M=29.34, S D=4.83)$ and female $(\mathrm{M}=29.86, \mathrm{SD}=3.27) ; \mathrm{t}(55)=-.45, \mathrm{p}=.66$; which again implies that gender has no role in accessing 'during treatment technology services' (DTTS) related to healthcare. This kind of result is quite natural because during medical treatments people want same kind of healthcare services irrespective of their gender.

(c) There is no significant difference in the dimension PDTS for male $(\mathrm{M}=36.34, \mathrm{SD}=4.84)$ and female $(\mathrm{M}=36.86, \mathrm{SD}=2.87) ; \mathrm{t}(55)=-.46, \mathrm{p}=.65$; which indicates that gender has no role in explaining post-discharge technology services (PDTS) related to healthcare. The reasons could be the similar ones as mentioned above ( $\mathrm{a}$ and $\mathrm{b}$ ).

Finally, in response to item number 19 of the questionnaire (I am willing to pay extra amount of money if hospital/healthcare centers will provide healthcare services which I can access through information technology or mobile applications. ............. Yes/No), the result indicate that out of 57 respondents, 35 responded (61.4\%) accepted that they are ready to pay extra amount of money for IT-enabled healthcare services which is very encouraging for the Indian economy.

\section{Conclusions, Implications, and Research Directions}

\subsection{Conclusions}

The present study has been initiated with an aim to understand the relevance and dimensions of information technology in the context of Indian healthcare system followed by linking these dimensions with some of the demographical variables such as age, gender, educational qualification, and income. At macro level, the study divulges the fact that people in India have a high inclination to use technology based healthcare services especially those services which are coupled with information technology. At micro level, the study highlights that there could be three dimensions of information technology that can be integrated in healthcare services. These dimensions cover a wide range of healthcare services in three different phases of medical treatments i.e., pre-visit to hospitals, during stay in hospitals and post-discharge facilities. Moreover, it has been found that income which is one of the demographical variables may be an important predictor in accessing technology based healthcare services in India. However, other three demographical variables (age, educational 
qualification, gender) are found insignificant in explaining respondents' inclination towards identified dimensions of information technology (PVTS, DTTS, and PDTS). In the light of the obtained results it may be summarized that 'Role of Information Technology in Indian Healthcare Services' is emerging as a vital issue which need to be discussed through integrated forums of healthcare professionals, academia, policy makers and government agencies. In conclusion, we would like to highlight that as most of the Indian population resides in rural area, associated stakeholders should think to train the users and service providers regarding healthcare information technology.

\subsection{Implications for Healthcare Professionals}

As the study highlights that visitors or patients are ready to pay extra amount of money if they are provided IT-enabled healthcare services, there is a huge scope for entrepreneurial opportunities to the companies which are working in the field of healthcare, information technology, and finance. Moreover, on the basis of some respondent's comments during data collection it is also suggested that healthcare technology should be developed by keeping the different languages and dialects of India on forefront so that even a common man living in villages can access it easily.

\subsection{Implications for Researchers}

We strongly believe that the present study is a novel one and contributes in the literature of healthcare technology and management. However, there are some limitations that must be acknowledged and accordingly addressed by the future researchers. First, the sample of the study is very less and unequal in gender. Therefore, future researchers are suggested to replicate the study in a large sample which includes sufficient male and female respondents. Second, as reliability of data privacy has been major concern (Lorence and Saylor, 2008) technology researchers must look into this carefully. Third, as we know that in India data related to individual's health has close relationship with social institutions especially with marriage system, ownership of healthcare data should be prioritized in the purview of legal boundaries. Fourth, technology adoption attitude and support from top management are crucial in implementing information technology application in healthcare services as espoused by Chaua and Hub (2002), therefore, a high level of synchronization is required among all the relevant stakeholders like medical professionals (doctors, nurses, administrative staff etc), training organizations, government, academia, and policy makers. Finally, we wish that the present study will leave no stone unturned in making Healthy India.

\section{References}

Ahmed, A., Mirza, E., Ehsan, N., Awan, S., A., and Ishaque, A. (2010). "Information Technology: A Means of Quality in Healthcare", 3rd IEEE International Conference on Computer Science and Information Technology, 9, 26-30, Retrieved from http://ieeexplore.ieee.org/document/5564669/

Alasaarela, E., DeMello, S., and Nemana, R. (2009). "National perspectives on the future of wireless in healthcare: Finland and the USA", Journal of Management and Marketing in Healthcare, 2(4), 366-383. https://doi.org/10.1179/mmh.2009.2.4.366

Bates, D. W., Cohen, M., Leape, L. L., Overhage, J. M., Shabot, M. M., and Sheridan, T. (2001). "Reducing the Frequency of Errors in Medicine Using Information Technology", Journal of the American Medical Informatics, 8, 299-308.

Behkami, N., A., and Daim T., U. (2012). "Research Forecasting for Health Information Technology (HIT), using technology intelligence", Technological Forecasting and Social Change, 79(3), 498-508.

https://doi.org/10.1016/j.techfore.2011.08.015

Bennett, C., J., Walston, S., L., and Al-Harbi, A. (2015). "Understanding the effects of age, tenure, skill, and gender on employee perceptions of healthcare information technology within a Middle Eastern Hospital", International Journal of Healthcare Management, 8(4), 272-280. https://doi.org/10.1179/2047971915Y.0000000010

Bhangale, V. (2011). "Marketing of healthcare services in India: a study on factors influencing patients' decision making on choice of a hospital", Journal of Management and Marketing in Healthcare, 4(4), 229-233. https://doi.org/10.1179/175330311X12943314049376

Buntin, M., B., Burke, M., F., Hoaglin, M., C., and Blumenthal, D. (2011). "The Benefits Of Health Information Technology: A Review Of The Recent Literature Shows Predominantly Positive Results", Health Affairs, 30(3), 464-471. https://doi.org/10.1377/hlthaff.2011.0178

Byrd, L., W., Byrd, T., A. (2012). "The impact of clinical information technology on information quality in US hospitals", International Journal of Healthcare Technology and Management, 13(1/2/3), 71-87. https://doi.org/10.1504/IJHTM.2012.048948

Chaua, P., Y., K., and Hub, P., J. (2002). "Investigating healthcare professionals' decisions to accept telemedicine technology: an empirical test of competing theories", Journal of Information and Management, 39(4), 297-311. https://doi.org/10.1016/S0378-7206(01)00098-2 
Cho, N., E., Ke, W., Atems, B., and Chang, J. (2016). "How Does Health Information Technology Affect Hospital Performance Efficiency? The Effects of Information Sharing Breadth and Depth", Pacific Asia Conference on Information Systems, Retrieved from aisel.aisnet.org

Chow, C., K. (2013). "Factors associated with the extent of information technology use in Ontario hospitals", International Journal of Healthcare Management, 6(1), $18-26$. https://doi.org/10.1179/2047971912Y.0000000017

Cline, G., B., and Luiz, J., M. (2013). "Information technology systems in public sector health facilities in developing countries: the case of South Africa", BMC Medical Informatics and Decision Making, 13(1), 13. https://doi.org/10.1186/1472-6947-13-13

Darkins, A., and Sanders, J., H. (2009). "Remote patient monitoring in home healthcare: Lessons learned from advanced users", Journal of Management and Marketing in Healthcare, 2(3), 238-252.

https://doi.org/10.1179/mmh.2009.2.3.238

Duplaga, M. (2004). "The Impact of Information Technology on Quality of Healthcare Services", International Conference on Computation Science, 3039, 1118-1125. https://doi.org/10.1007/978-3-540-25944-2_145

Farhud, D. D. (2015). "Impact of Lifestyle on Health", Iranian Journal of Public Health, 44(11), 1442-1444.

Henschke, C., Bäumler, M., Weid, S., Gaskins, M., and Busse, R. (2010). "Extrabudgetary ('NUB') payments: A gateway for introducing new medical devices into the German inpatient reimbursement system", Journal of Management \& Marketing in Healthcare, 3(2), 119-133. https://doi.org/10.1179/175330310X12665793931221

Herrick, D., M., Gorman, L., and Goodman, J., C. (2010). "Health Information Technology: Benefits and Problems", National Center for Policy Analysis, Policy Report No. 327, Retrieved from http//www.ncpa.org/pdfs/st327.pdf

Huang, W., M., Chen, C., H., Lin, H., R., and Sun, C., F. (2016). "Decision support system for material management in intensive care units: An empirical study in Taiwan", International Journal of Healthcare Management, 9(2), 102-109.

https://doi.org/10.1080/20479700.2015.1101912

India Brand Equity Foundation (2017). Healthcare Industry in India. Retrieved from

https://www.ibef.org/industry/healthcare-india.aspx

Itumalla, R. (2012) "Information Technology and Service Quality in Health Care: An Empirical Study of Private Hospital in India”, International Journal of Innovation,
Management and Technology, 3(4), 433-436, Retrieved from www.ijimt.org/papers/269-CM248.pdf https:// doi.org/10.7763/IJIMT.2012.V3.269

Kaushal, R., Shojania, K. G., Bates, D. W. (2003). "Effects of computerized physician order entry and clinical decision support systems on medication safety: a systematic review", Archives of Internal Medicine, 163(12), 1409-1416. https://doi.org/10.1001/archinte.163.12.1409

Kavitha, G. (2013). "Impact of information technology in Indian healthcare system", International Journal of Engineering and Technology (IJET), 5(1), 110-114.

Kelishadi, R. (2012). "Environmental Pollution: Health Effects and Operational Implications for Pollutants Removal", Journal of Environmental and Public Health, 2012, Retrieved from http://dx.doi.org/10.1155/2012/341637

Khanna, A., B., and Narula, S., A. (2016). "Mobile health units: Mobilizing healthcare to reach unreachable", International Journal of Healthcare Management, 9(1), 58-66.

https://doi.org/10.1080/20479700.2015.1101915

Koop, R., H., Klaase, J., M., Palen, J., v., Kommers, P., A., M., Sanders, A., J., and Jonker, J. (2010). "Using a web application to improve satisfaction among patients undergoing surgery", International Journal of Healthcare Management, 3(4), 264-271. https://doi.org/10.1179/175330310X12918040319694

Kumar, R. R., and Iyengar, N.Ch.S.N. (2014). "Secure and synchronised mobile JXTA cloud ecosystem for sharing patient's healthcare information and medical reports", International Journal of Computers in Healthcare, 2(1), 15-27. https://doi.org/10.1504/IJCIH.2014.065809

Li, X., Agarwal, A., Hadidi, R., and He, X. (2012). "Quality analysis of online health information in China, India, and the USA", International Journal of Healthcare Technology and Management, 13(1/2/3), 117-138. https://doi.org/10.1504/IJHTM.2012.048951

Lorence, D., and Saylor, K. (2008). "Study of web-based peer discussion: the domain of scleroderma", International Journal of Healthcare Technology and Management, 9(3), 275-302.

https://doi.org/10.1504/IJHTM.2008.018218

Lu, K., Y. (2012). "Enhancing the performance of healthcare services using a ZigBee-based mobile monitoring system", International Journal of Healthcare Technology and Management, 13(1/2/3), 88-107. https://doi.org/10.1504/IJHTM.2012.048949

Masella, C., and Zanaboni, P. (2009). "Assessment of a telemedicine innovation in cardiology", International 
Journal of Healthcare Technology and Management, 10(4/5), 325-339.

https://doi.org/10.1504/IJHTM.2009.030454

Masys, D., R. (2002). "Effects of Current and Future Information Technologies on the HealthCare Workforce", Health affairs, 21(5), 33-41.

https://doi.org/10.1377/hlthaff.21.5.33

Mehraeen, E., Ahmadi, M., Mehdipour, Y., and Noori, T. (2014). "Evaluation of Hospital Information Systems in Selected Hospitals of Iran", International Journal of Advanced Information Technology (IJAIT), 4(5), 1-7, Retrieved from

http://airccse.org/journal/IJAIT/papers/4514ijait01. pdf https://doi.org/10.5121/ijait.2014.4501

Miah, S., J. (2014). "Information and communication technology-based innovations for aging healthcare: a literature review", International Journal of Computers in Healthcare, 2(1), 28-42.

https://doi.org/10.1504/IJCIH.2014.065810

Moghavvemi, S., Ormond, M., Musa, G., Isa, C., R., M., Thirumoorthi, T., Mustapha, M., Z., B., Kanapathy, K., A., P., and Chandy, J., J., C. (2016). "Connecting with prospective medical tourists online: Across-sectional analysis of private hospital websites promoting medical tourism in India, Malaysia and Thailand", Tourism Management, 58, 154-163. https://doi.org/10.1016/j.tourman.2016.10.010

Mohapatra, S. (2015). "Using integrated information system for patient benefits: a case study in India", International Journal of Healthcare Management, 8(4), 262-271. https://doi.org/10.1179/2047971915Y.0000000007

Mohapatra, S. and Murarka, S. (2016). "Improving patient care in hospital in India by monitoring influential parameters", International Journal of Healthcare Management, 9(2), 83-101.

https://doi.org/10.1080/20479700.2015.1101938

Mosadeghrad, A., M. (2014). "Factors influencing healthcare service quality", International Journal of Health Policy and Management, 3(2), 77-89. https://doi.org/10.15171/ijhpm.2014.65

Noblin, A., M. Wan, T., T., H. and Fottler, M. (2013). "Intention to use a personal health record: a theoretical analysis using the technology acceptance model", International Journal of Healthcare Technology and Management, 14(1/2), 73-89.

https://doi.org/10.1504/IJHTM.2013.055085

Ohsfeldt, R. L., Ward, M. M., Schneider, J. E., Jaana, M., Miller, T. R., Lei, Y. and Wakefield, D., S. (2005). "Implementation of hospital computerized physician order entry systems in a rural state: Feasibility and financial impact", Journal of the American Medical Informatics. 12(1), 20-27.

https://doi.org/10.1197/jamia.M1553

Ornes, L. L., Paulson, P. and Snyder, K. (2014). "A tool to evaluate your website for patient engagement", International Journal of Healthcare Management, 7(2), 69-74.

https://doi.org/10.1179/2047971913Y.0000000066

Ortiz, E. and Clancy, C., M. (2003). "Use of Information Technology to Improve the Quality of Health Care in the United States", Journal of Health Services Research, 38(2), xi-xxii.

https://doi.org/10.1111/1475-6773.00127

Patwardhan, A. A., Pandey, N. and Dhume, S., M. (2017). "Integrated model for understanding Indian physicians' internet usage pattern: An empirical approach", International Journal of Healthcare Management, 10(1), 19-33.

https://doi.org/10.1080/20479700.2016.1270385

Pillai, R., K. (2013). "Health economics: Theoretical considerations and scope for application in the Indian context", Clinical Epidemiology and Global Health, 1(2), 96-100.

https://doi.org/10.1016/j.cegh.2013.05.002

Pui-Mun, L. (2004). "IT-Enhanced Service Quality in the Healthcare Industry", International Journal of the Computer, the Internet and Management, 12(3), 96-103.

Rajasekaran, M. P., Radhakrishnan, S., Subbaraj, P. (2008). "Remote monitoring of post-operative patients using wireless sensor networks", International Journal of Healthcare Technology and Management, 9(3), 247-257.

https://doi.org/10.1504/IJHTM.2008.018216

Remoundou, K., and Koundouri, P. (2009) "Environmental Effects on Public Health: An Economic Perspective", International Journal of Environmental Research and Public Health, 6(8), 2160-2178; doi:10.3390/ ijerph6082160 https://doi.org/10.3390/ijerph6082160

Rizwan, S. A., Nongkynrih, B., Gupta, S. K., (2013). "Air pollution in Delhi: Its Magnitude and Effects on Health", Indian Journal of Community Medicine, 28(1), 4-8.

Roehrer, E., Bjørnes, C. D., Cummings, E. and Nøhr, C. (2014). "Human factors considerations when developing eHealth solutions to support patients : Comparison of Danish and Australian experiences", International Journal of Healthcare Technology and Management, 14(3), 157-175. https://doi.org/10.1504/IJHTM.2014.064245 
Schultz, J. S., André, B. and Sjøvold, E. (2016). "Managing innovation in eldercare: A glimpse into what and how public organizations are planning to deliver healthcare services for their future elderly", International Journal of Healthcare Management, 9(3), 169-180. https://doi.org/10.1080/20479700.2016.1142048

Seblega, B. K., Zhang, N. J., Wan, T. T. H., Unruh, L., Y. and Miller, A. (2015). "Health information technology adoption: effects on patient safety and quality of care", International Journal of Healthcare Technology and Management, 15(1), 31-48.

https://doi.org/10.1504/IJHTM.2015.070519

Sintonen, S. Mäkelä, K. Miettinen, R. (2015). "User acceptance of electronic health records: a postimplementation study", International Journal of Healthcare Technology and Management, 15(2), $162-175$.

https://doi.org/10.1504/IJHTM.2015.074556

Srinivas, T. R. and Prasad, S. (2013). "Evaluation of Healthcare Services "Why Did We Choose This Hospital?" Language in India, 13(4), 259-268.

Stanley, S. and Laugharne, J. (2014). "The impact of lifestyle factors on the physical health of people with a mental illness: a brief review", International Journal of Behavioral Medicine, 21(2), 275-81. https://doi.org/10.1007/s12529-013-9298-x

Steiner, P. (2014) "Investment in health technologies calls for lessons to be learned", International Journal of Healthcare Management, 7(1), 3-4. https://doi.org/10.1179/2047970014Z.00000000088

Testi, A., Tanfani, E., Valente, R., Fato, M., and Porro, I. (2009). "A web-based system to manage elective waiting lists: efficiency and equity issues", International Journal of Healthcare Technology and Management, 10(4/5), 277-288. https://doi.org/10.1504/IJHTM.2009.030451

Thangaraj, M. and Gnanambal, S. (2014). "A new architectural framework for rule-based healthcare system using semantic web technologies", International Journal of Computers in Healthcare, 2(1), 1-14. https://doi.org/10.1504/IJCIH.2014.065808

Themistocleous, M. and Morabito, V. (2012). "How can user-centred design affect the acceptance and adoption of service oriented healthcare information systems", International Journal of Healthcare Technology and Management, 13(5/6), 321-344.

https://doi.org/10.1504/IJHTM.2012.052550
Thomas, L. and Woodside, J., M. (2016). "Digital and mobile experiences for healthcare management: Social media maturity model", International Journal of Healthcare Management, 9(1), 67-73. https://doi.org/10.1080/20479700.2015.1101940

Times of India (2017). "Health ministry to study deaths due to pollution soon: Environment Minister Anil Dave", Retrieved from http://timesofindia.indiatimes.com

Venkateswaran, P. S., Kumar, V. R. and Muthukrishnan, B. (2016). "Impression of Telemedicine on Patient Happiness on the way to health Services", Asian Journal of Research in Social Sciences and Humanities, 6(11), 136-157. https://doi.org/10.5958/2249-7315.2016.01181.3

Walsh, R. (2011). "Lifestyle and mental health", American Psychologist, 66(7), 579-592 https://doi.org/10.1037/a0021769

Wang, D. (2015). "What will cloud computing bring to healthcare? - Overview of cloud applications in healthcare", International Journal of Healthcare Technology and Management, 15(1), 49-57. https://doi.org/10.1504/IJHTM.2015.070540

Whetstone, M. and Randeree, E. (2008). "Personal health records: addressing consumer needs for access", International Journal of Healthcare Technology and Management, 9(3), 258-274.

https://doi.org/10.1504/IJHTM.2008.018217

Wijewickrama, A. K. A. and Takakuwa, S. (2012). "Designing outpatient appointment systems with patient characteristics: a case study", International Journal of Healthcare Technology and Management, 13(1/2/3), 157-69. https://doi.org/10.1504/IJHTM.2012.048953

World Health Resolution (67/13): Aging and Health (2015), Retrieved from http://www.who.int/mediacentre/ factsheets/fs404/en.

Zhan, X. X., Zhang, Z. X., Sun, F., Peng, W. J., Zhang, H. and Yan, W., R. (2016). "The attitudes of primary healthcare providers towards web-based training on public health services in rural China: a cross-sectional study", Public Health, 141, 153-162. https://doi.org/10.1016/j.puhe.2016.09.007 